\title{
Research on PPP Financing Model of Ecological Compensation
}

\author{
ZHANG Ming-kai \\ Faculty of Management and Economics, Kunming University of Science and Technology, Kunming 650 \\ 093
}

Keywords: Ecological Compensation; PPP Financing Model

\begin{abstract}
. ecological compensation is an effective means of protecting the ecological environment and promoting the harmonious development of man and nature, foreign countries often adopt the way of market compensation based on the perspective of the market compensation and get the better effect; however, in China, due to the reason of system, most of them rely on the government compensation, which can result in the lack of funds for compensation with the low compensation efficiency, therefore, the effect of compensation is limited. At present, domestic parties are actively exploring the mechanism of market compensation, the key of market mechanism is the funding sources of compensation. Therefore, in this paper, it takes resolving this problem as the starting point, making analysis on the advantages and disadvantages of the compensation funds that mainly relies on the government in China, through making comparative analysis, drawing lessons from domestic and international practice and views, putting forward the PPP financing model of ecological compensation, analyzing its necessity and feasibility, exploring and discussing the operating mechanism, so as to solve the problem of the source of compensation funds, which can have theoretical and practical significance.
\end{abstract}

The characteristics of ecological resources of public goods makes the usage of ecological resources and consumption be non exclusive, which can result in the "tragedy of the public places", thus, the ecological environment is destroyed seriously, environmental problems such as air pollution, water pollution and so on become serious threat to human survival and development, therefore, one of the effective means for solving this problem is the ecological compensation, all over the world has reached a consensus. At present, China's ecological compensation in theory is still stressing the feature of public ecosystem service, paying attention to the necessity feature of government for purchasing the ecological compensation, however, it neglects the role of the mechanism of market, which can result in the absence of research on incentive and constraint mechanism of the ecological compensation, making the state of ecological compensation have low degree of market in practice,with the shortage of ecological compensation funds, low compensation efficiency and effectiveness as well. Although China has recognized the importance of the market mechanism, it still takes a long process from theory to practice. In this paper, it take the market mechanism as the starting point, making analysis on the advantages and disadvantages of ecological compensation funds, putting forward the PPP model of ecological compensation for raising funds, making research on ecological compensation and using PPP financing model to introduce market mechanism with the social capital, which can not only solve the source of funds for the ecological compensation, but also can improve the ecological compensation efficiency as well as effect, thus, it can play a guiding role both in theory and practice.

\section{Analysis on the Advantages and Disadvantages of Government's Compensation Funds}

Due to the different ownership structure as well as different operation of market mechanism with foreign countries, the means of ecological compensation in China is mainly in government leading model, which still relies on the government to provide funds for ecological compensation, besides, the government financing sources are mainly in four ways: financial transferring payment, issuing bonds, taxing, ecological compensation funds and so on. The advantages and disadvantages of the compensation funds provided by the government can be summarized as follows: 


\subsection{Analysis on the Advantages of the Government Financial Support}

The advantages of the government dominated model are as follows:one aspect is that the financial strength is large for the investment in a certain field of ecological compensation, such as "the establishment of natural reserve" and "returning farmland to forest (grass) project" and so on, with high efficiency of capital turnover, raising funds quickly, using flexibly at local cities, with more obvious effects, which can be in line with the characteristics of Chinese ownership. Another aspect is that, compared with the market mechanism, the cost of transaction is low. The third aspect is without the scientific evaluation on the value of ecological resources and ecological services, it is undoubtedly that the best way for compensation is by government funds, although there may cause excessive consumption and ecological deterioration because of the too low ecological resources pricing that is fixed by the government, as well as the ecological surroundings can not be effectively controlled, however, at least the ecological compensation has been partially implemented, once it simply relies on the market to compensate, there is almost no investors who are willing to compensate the cost of natural resources and ecological services, because from the view of the return of the investment, the market mechanism can rely on social capital to solve the problem of the shortage of ecological compensation funds, thus, the criteria of social capital investment is up to the size of the return of the investment, although the great value of the ecological environment has been recognized by the vast majority of people, but its value is difficult to measure the size as well as the currency, at present, there is no effective way to have science evaluation, therefore, it has the nature of public welfare, unless the government can give sufficient preferential policies and support, otherwise it can not solve the problem simply rely on the market.

\subsection{Analysis on the Disadvantages of the Government Financial Support}

The disadvantages can be reflected in the following aspects: one aspect is that the source of compensation funds is single, the amount of the compensation funds that government can provide is limited, therefore, the coverage of compensation is limited, in most of fields, the amount of the compensation is not enough, which can not meet the needs of protecting and constructing the ecological environment. Another aspect is that it can keep the ecological beneficiaries and protectors out of touch, which is quite contrary to the principle of"who benefits who makes compensation", it is difficult to reflect the unity of the right, responsibility, benefit of the subject of the ecological compensation. The third aspect is that due to the limited rationality of the government decision-making and insufficient funds, the price of the compensation is too low, which can not play its proper role. The fourth aspect is that the regional difference is significant, due to the lack of funds, it has not really established diversified financing mechanism and ecological compensation fund system the with coordination of government, society and market, which can result in the heavy financial burden, fiscal transferring payment will be lack of stability. In particular some less developed places such as central and western regions, the financial income of the local government is limited, which is difficult to carry out the ecological compensation transferring payments.

\section{Analysis on PPP Financing Model of Ecological Compensation}

\subsection{Brief Introduction of PPP Model}

The origin of PPP model can be originated from the United Kingdom in the 1980s, so far, both the domestic and foreign experts and scholars as well as organizations can not have clear definition about PPP, there is no unified definition, PPP is the abbreviation of Public Private Partnership, the literal translation can refer to the partnership between the public part and the private part. It is generally believed that PPP can have both broad sense and narrow sense, as for its broad sense, PPP is the financing model with public and private investment, which can be classified in a variety of ways, such as BT, BOO, TOT, BOT and so on. As for the narrow sense of PPP, it is a new exploring way in recent years developed countries such as UK, so as to make up for the deficiency of BOT and PFI model, which is similar to the principle of BOT, namely, "user pays", but it pays more emphasis on the cooperation of the whole process of the public part and private part than that of BOT, which is SPV (Special-Purpose-Vehicle, namely, the special purpose institution/company) 
composed by government and business, moreover, the rights and obligations of the government and enterprises is equal and limited. At present, PPP is in the pilot stage in our country, which is in the ascendant trend. The introduction of PPP into the field of ecological compensation for the application, which can be innovative in theory.

\subsection{The Necessity of PPP Financing Model of Ecological Compensation}

Because in our country, the view of public on ecological resources usage and consumption has held the attitude of the public goods. Therefore, during the period of having economic development, at the same time, it did not take the ecological resources construction and ecological protection into account, which can lead to the increased ecological deterioration phenomenon gradually, although country has made great efforts in order to improve the ecological environment, due to the constraints of funds and strength, the changes of public consciousness as well as the lagging practical action, the trend of deterioration of the ecological environment didn't get effective control, in order to protect the ecological environment and promote the harmonious development of man and nature, it is urgent to establish a scientific and perfect ecological compensation system. One of the core problems of ecological compensation is the source of compensation funds, this problem can determine the ecological compensation mechanism to a certain extent, which also can determine the efficiency and effectiveness of ecological compensation, in view of the above analysis of the disadvantage of relying on the government to provide compensation funds singly, it is thought that it should adopt market-oriented compensation mechanism, under the support and guidance of the government, relying on the force of market to solve the problem of the lack of ecological compensation funds, so as to improve the management level and efficiency of compensation.

\subsection{The Feasibility of PPP Financing Model of Ecological Compensation}

The feasibility of ecological compensation to adopt PPP financing model lies in: (1) the practice of PPP financing model is mainly used in the construction of public infrastructure, public goods and public services, part of public infrastructure and public service as well as ecological compensation has the public nature, after the completion of the project, it has the operating characteristics, taking the more common points into account, the operation of PPP in the field of ecological compensation is feasible; (2) the existing practice of most of the successful PPP projects can provide support for the specific application of the model; (3)the government's policy guidance can provide policy support for the choice of the model of the state and local governments for promoting the application of the model, at present, both country and local government promote the application of this kind of model strongly, with the continuous accumulation of experience, as well as the breakthrough of theory, the application scope of this model will be used more and more widely in theoretical research; (4) some experts and scholars provide ideas for the source of the topic; (5) the source of compensation funds is a major problem of ecological compensation, it is necessary to design a mechanism to introduce the social capital into the ecological compensation,or to establish a financing platform, therefore, PPP itself is a more appropriate choice. (6) PPP itself is a public-private partnership model, which can be in line with the requirements of the cooperation between government and social capital.

\subsection{The Operation Mechanism of PPP Financing Model of Ecological Compensation}

The introduction of PPP financing model of ecological compensation, the key is to construct its operating mechanism. The construction of the operation mechanism can be including the following aspects: (1) the government and the private part can negotiate the cooperation content and way together on ecological compensation of a certain object such as forests, mines, lakes, basin and so on, which is the key whether it ca. use PPP or not, the content of cooperation should combine the tripartite interests of government, public and investors, the ultimate goal of which is to protect the ecological environment. In China, government is the owner of the ecological resources, which has the right to sell the ecological resources or ecological service value, investors use the government to sell the rights, under the premise without destroying the ecological environment, so as to develop the value of ecological resources and services for investment. The gains that are obtained can be under the supervision of the government or by the government to compensate for the loss of compensation for public interest, so as to solve the various problems of government compensation 
and reach the ultimate goal of ecological compensation. Taking the forest as an example, the government can sell a piece of land with its development rights to the private part, under the premise that the private part keep the maintenance and development of ecological forest, it can develop the value of forest, thus, part of the gains can make compensation for forest protection and damages to the interests of the local people, as for the government, in this way, it can not only solve the problem of the shortage of funds, it can also make compensation for the public, so as to protect the ecological environment, meanwhile, the private investors can also receive the gains, thus, it can take the interests of all parties into account. (2) the government part and the private part can be involved in the early demonstration and the late construction, with equal rights and obligations, which is quite different with the other financing models and other projects. (3) the government can play the role of policy support and supervision, while private capital is responsible for investment, the two sides can set up SPV specifically, which can be responsible for the design, financing, construction and operation of the entire project.

\section{Conclusion}

In this paper, it analyzes the advantages and disadvantages of the ecological compensation funds that is provided by the government at present,believing that market compensation mechanism is a feasible method in the future, the key to the market mechanism is the source of funding, therefore, combined with the theory and practice both at home and abroad, it has proposed PPP model of ecological compensation financing, meanwhile, demonstrating the necessity and feasibility of the model , finally discussing the operation mechanism of PPP model as well. Thus, it can play a guiding role in the development of ecological compensation. The construction of operation mechanism is very difficult, and the problems need to be solved are more, which can be used as the content of having further research.

\section{Reference}

[1] Shen Ling, wang Juan. Theory of project financing mode of the beijing-tianjin-hebei int erregional eco-compensation [J]. Journal of modern business, 2015, 28.

[2] wang cong. Theory of BOT financing mode in raising funds for forest ecological benefi $\mathrm{t}$ compensation [J]. Journal of green China, 2004 practices.

[3] Wang Louyu, Ren Shan English. Ecological compensation suggests research [J]. JNorthe rn Economy and Trade , 2013, 11.

[4] Huang Huan. Theory of the construction of ecological compensation diversified social $\mathrm{f}$ inancing system [J]. Journal of modern economy, 2013,09.

[5] cheng-liang wu, Wu Xiaoping, song Yang. The wetland ecological benefit compensation financing analysis [J]. Journal of forestry economy, 2013.07.

[6]. Sun suggests problems of ecological compensation explore [J]. Journal of qinghai financ ial, 2009.06.

[7] Jinlan Li., xuan-rui huang, yu-chen chang, qiu-juan li. China's forest ecological benefit c ompensation system adopts the BOT financing method to investigate [J]. Journal of green a ccounting, 2008.04. 